\title{
Assessment of health-promoting lifestyle profile in Japanese university students
}

\author{
Chang-Nian Wei $\cdot$ Koichi Harada $\cdot$ Kimiyo Ueda $\cdot$ \\ Kumiko Fukumoto $\cdot$ Keiko Minamoto • \\ Atsushi Ueda
}

Received: 9 March 2011 / Accepted: 20 September 2011/Published online: 11 October 2011

(C) The Japanese Society for Hygiene 2011

\begin{abstract}
Objectives This descriptive study of 314 students was conducted to determine whether there were any relationships of their demographic variables with a health-promoting lifestyle profile.

Methods The Japanese version of the Health Promoting Lifestyle Profile II (HPLP-II) questionnaire was used to investigate students' lifestyles. One-way analysis of variance (ANOVA) and multiple comparison procedures using the Scheffe test were conducted to identify significant differences among university year (first, second, etc.) groups. The $t$-test independent participants was utilized to compare the HPLP-II scores according to gender and living with family (yes/no). Multiple regression analysis was used to analyze the effects of various demographics on the overall HPLP-II score and the six health-promoting lifestyle subscales.

Results The whole cohort of participants had an overall HPLP-II mean score of 2.50 ( $\mathrm{SD}=0.29$ ), with the highest mean score being for interpersonal relations $(3.05 \pm 0.44)$, and the lowest mean score being for health responsibility $(2.01 \pm 0.53)$. The overall HPLP-II score of the students during the first university year was $2.59(\mathrm{SD}=0.29)$, and
\end{abstract}

C.-N. Wei $(\bowtie) \cdot$ K. Minamoto $\cdot$ A. Ueda

Department of Preventive and Environmental Medicine, Faculty of Life Sciences, Kumamoto University, 1-1-1,

Honjo, Kumamoto 860-8556, Japan

e-mail: cnwei@kumamoto-u.ac.jp

K. Harada $\cdot$ K. Ueda

Department of Biomedical Laboratory Sciences,

Faculty of Life Sciences, Kumamoto University,

Kumamoto, Japan

K. Fukumoto

Kyushu University of Nursing and Social Welfare,

Tomio Tamana, Kumamoto, Japan this score progressively declined in their second year $(2.49 \pm 0.29)$, third year $(2.47 \pm 0.28)$, and fourth year $(2.45 \pm 0.30)$. Female students practiced significantly better health responsibility, interpersonal relations, and nutrition than males, and male students practiced significantly better physical activity than females. The students who were living with family had significantly higher nutrition scores than those not living with family.

Conclusions These significant findings linking the HPLPII, university year level, and living with family (yes/no) in university students will enable healthcare providers to develop interventions to assist students in improving their health lifestyles in the university environment and will help in devising suitable education programs.

Keywords Health-promoting lifestyle profile II . Health behaviors - University year (first, second, etc.) · University students $\cdot$ Lifestyle

\section{Introduction}

A health-promoting lifestyle is an important determinant of health status. In the United States and Japan, plans such as "Healthy People 2010" [1], "Healthy Japan 21" [2], and "Healthy Campus 2010" [3] have been designed to enhance the quality of life of citizens, improving their lifestyles through health-promotion programs. In the Healthy Japan 21 plan, even though the health-promotion projects cover the entire life span and involve all periods of life from the fetal stage (including the health of the expectant mother) to infancy, childhood, puberty, and adolescence, young adulthood, middle and late middle age, and advanced and late advanced age, the population of university students has been widely neglected as a target 
group. University students are not viewed as a priority for health-promotion efforts in Japan. However, many college students are living away from home for the first time. They are faced with the responsibility for their personal health, lifestyle, and behaviors. Young adults develop behaviors that may remain part of their lifestyle into adulthood [4] or that may jeopardize their health status in later life.

University students are in a dynamic transition period of growth and development that bridges adolescence (high school students) and adulthood (people in the community). This period sees many rapid changes in the body and mind, and in social relationships [5]. At this stage, there are various difficult life conditions and different lifestyles in the university environment. With the changes in study style and unfamiliar life conditions, many students engage in a wide range of unhealthy habits, such as inadequate nutritional intake, rest, and exercise [6-10].

Many studies have reported the relationships among demographic variables and health-promoting behaviors. However, no studies have found relationships between university year (first, second, etc.) and health-promoting behaviors. The purpose of this study was to determine whether or not there were any relationships between university students' age, gender, whether or not they were living with family, body mass index (BMI), and their year level with their overall score on the Health Promoting Lifestyle Profile II (HPLP-II) instrument and six healthpromoting lifestyle subscales [health responsibility (HR), spiritual growth (SG), physical activity (PA), interpersonal relations (IR), nutrition (N), and stress management (SM)]. It is hoped that the results of this study will provide information to university administrators and teachers for general education program awareness (modification), and help students to adopt a healthy lifestyle, thus promoting the health of individuals and the population of Japan.

\section{Methods}

Participants and instruments

The data were collected from students in their first university year in the academic year, 2008. A cross-sectional research method was adopted. Questionnaires were distributed during class by a research assistant not involved in teaching the students. To ensure anonymity, no name was required on the questionnaire and it was returned during class to a designated box. Participants were asked to complete a self-administered questionnaire with two sections specifically designed for the study. The first section was related to demographic variables. They also were asked to report their weight and height in order to calculate their body mass index (BMI). The BMI was calculated as the weight divided by the height squared $\left(\mathrm{kg} / \mathrm{m}^{2}\right)$. An obesity classification system [11] was used to categorize participants according to their BMI: underweight $(<18.5)$; normal weight (18.5-24.9); overweight $(>25)$. The second section of the questionnaire was on health promotion attitudes and health practices, as reflected in the HPLP-II instrument developed by Walker et al. [12]. The HPLP-II was translated into the Japanese language by Wei et al. [13], and the reliability and validity of the translated version has been demonstrated.

The HPLP-II instrument has 52 health-promoting behaviors categorized into six health-promoting lifestyle subscales: (1) health responsibility (HR), (2) spiritual growth (SG), (3) physical activity (PA), (4) interpersonal relations (IR), (5) nutrition (N), and (6) stress management (SM). A 4-point response scale consisting of 1 representing "never", 2 representing "sometimes", 3 representing "often", and 4 representing "routinely" was used to determine the frequency of each behavior. A mean of $\geq 2.50$ was considered to be a positive response, in line with a previous study [14].

Data collectors administered the questionnaire in the classroom. The students were informed about the purpose of the study and their informed consent was obtained; they were instructed that participation was voluntary and that information provided would be confidential. Survey procedures were designed to protect students' privacy and to allow for anonymous participation. The study was conducted in the faculties of medicine, pharmacy, education, science, engineering, culture, and law, which adequately represented the subjects studying general education programs at Kumamoto University, Japan. Age, gender, year of university study, whether or not they were living with family, and income from regular or part-time jobs were self-reported by the participants.

This study was conducted after obtaining informed consent from all subjects and approval from the ethics committee of Kumamoto University Faculty of Life Sciences (approval number 408), and this study was performed in accordance with the Declaration of Helsinki.

\section{Analysis}

Data were analyzed using the Statistical Package SPSS version 17 (SPSS). One-way ANOVA and multiple comparison procedures using the Scheffe test were conducted to identify significant differences among year groups. The $t$-test independent participants was utilized to compare the HPLPII scores according to gender and living with family (yes/no). Multiple regression analysis was used to examine the effects of the six independent variables (age, gender, whether living with family or not, income, year, and BMI) on the seven dependent variables (the overall HPLP-II score and the six health-promoting lifestyle subscales). In the analysis of 
health-promoting lifestyles, only those who reported "often" or "routinely" employing each health practice item were considered as practicing a health-promoting lifestyle. Participants who reported "never" or "sometimes" were considered as not practicing the health-promoting lifestyles. The $\chi^{2}$ test was used for comparing percentages of male and female participants who reported "often" or "routinely" employing a health-promoting lifestyle. Pearson's correlation analysis was used to determinethe relationship of year levels with the overall HPLP-II score and BMI. A $P$ value of 0.05 was regarded as significant.

\section{Results}

Demographic characteristics of participants

The survey participants consisted of 336 students (161 males, 175 females) with the gender ratio reflecting that of the total university population. Three hundred and fourteen students completed the questionnaire (the response rate was $93.5 \%$ ). Table 1 shows the demographic data of the participants. One hundred and seventy survey questionnaires were returned from first year students, representing a $79.1 \%$ response rate. The second year students returned 67 surveys or $88.2 \%$. The third year students returned 31 surveys or $71.8 \%$. The fourth year students returned 46 surveys or $100 \%$. The mean age of the respondents was $20.1 \pm 1.5$ years (range 18-34 years; the upper end of the range was represented by one 34-year-old third year student). A significant difference existed between the years in age $(F=45.77, P<0.001)$.

Year of university study

As shown in Table 2, for all students, the overall HPLP-II mean score was $2.50 \pm 0.29$. Among the six health-

Table 1 Demographics of the participants $(n=314)$

\begin{tabular}{lcl}
\hline Variable & Percentage $(n)$ & Age, years $($ mean \pm SD) \\
\hline Gender & & \\
Male & $62.4(196)$ & $19.1 \pm 1.6$ \\
Female & $37.6(118)$ & $18.7 \pm 1.1$ \\
Year & & $18.6 \pm 1.6$ \\
First & $54.1(170)$ & $19.4 \pm 0.8$ \\
Second & $21.3(67)$ & $20.7 \pm 0.9$ \\
Third & $9.9(31)$ & $21.7 \pm 0.8$ \\
Fourth & $14.7(46)$ & \\
Living with family & & $18.7 \pm 1.1$ \\
Yes & $53.5(168)$ & $18.7 \pm 1.1$ \\
No & $46.5(146)$ &
\end{tabular}

promoting lifestyle subscales, the highest mean score was for IR $(3.05 \pm 0.44)$, and the lowest mean score was for HR $(2.01 \pm 0.53)$. The first year students showed higher scores for overall HPLP-II $(2.59 \pm 0.29)$, SG $(2.70 \pm$ $0.47)$, PA (2.31 \pm 0.56$)$, IR (3.16 \pm 0.39$), \mathrm{N}(2.59 \pm$ $0.41)$, and SM (2.77 \pm 0.47$)$ than students in other years, but HR $(2.02 \pm 0.48)$ was not higher than that for the students in other years. The first year students and second year students engaged significant more frequently in PA than third year students and fourth year students. Pearson's correlation analysis showed a significant negative correlation between the overall HPLP-II score and year $(r=$ $-0.169, P<0.01)$.

The $\chi^{2}$ test analysis showed that there were significant differences between the year level and some health-promoting behaviors in the subscales. More first year students ( $n=37,21.8 \%)$, second year students $(n=28,41.8 \%)$, and third year students $(n=9,29.0 \%)$ than fourth year students $(n=2,4.3 \%)$ reported "follow a planned exercise program" $(n<0.001)$. The same pattern was found for items such as "exercise vigorously for 20 or more minutes at least three times a week" $(33.5,34.3,22.6$, and $4.3 \%$ for years $1-4$, respectively, $P<0.01$ ), "take part in light to moderate physical activity" $(20.6,20.9,25.8$, and $4.3 \%$ for years $1-4$, respectively, $P<0.01$ ), "take part in leisuretime" $(17.6,14.9,12.9$, and 2.2 for years $1-4$, respectively, $P<0.01)$, "do stretching exercises at least 3 times per week" $(26.5,28.4,22.6$, and $15.2 \%$ for years 1-4, respectively, $P<0.01$ ), and "get exercise during usual daily activities" $(37.1,26.9,22.6$, and $10.9 \%$ for years $1-4$, respectively, $P<0.01)$. The first year students were more capable than students in other years in interpersonal relations items, such as "praise other people easily for their achievements" $(39.4,26.9,19.4$, and 30.4 for years 1-4, respectively, $P<0.05)$; "maintain meaningful and fulfilling relationships with others" $(42.9,43.3,35.5$, and $19.6 \%$ for years $1-4$, respectively, $P<0.01)$; "spend time with close friends" $(37.1,26.9,29.0$, and $19.6 \%$ for or years $1-4$, respectively, $P<0.01)$; and "touch and am touched by people I care about" $(41.2,41.8,9.7$, and $17.4 \%$ for years $1-4$, respectively, $P<0.01)$.

\section{Gender}

The males had an overall HPLP-II mean score of $2.50 \pm$ 0.32 , while the females had an overall HPLP-II mean score of $2.51 \pm 0.25$. No significant difference existed between the male and female students in the overall HPLP-II score $(t=0.789 ; P>0.05)$. Female students practiced significantly better HP $(t=2.757 ; P<0.01)$, IR $(t=2.550$; $P<0.05)$, and $\mathrm{N}(t=2.872 ; P<0.01)$ than males, and male students practiced significantly better PA $(t=5.276$; $P<0.001$ ) than females (Table 3). 
Table 2 Distribution of health-promoting lifestyle profile II (HPLP-II) scores according to year

\begin{tabular}{|c|c|c|c|c|c|c|c|}
\hline Year & $\begin{array}{l}\text { Overall } \\
\text { HPLP-II }\end{array}$ & $\begin{array}{l}\text { Health } \\
\text { responsibility }\end{array}$ & $\begin{array}{l}\text { Spiritual } \\
\text { growth }\end{array}$ & $\begin{array}{l}\text { Physical } \\
\text { activity }\end{array}$ & $\begin{array}{l}\text { Interpersonal } \\
\text { relations }\end{array}$ & Nutrition & $\begin{array}{l}\text { Stress } \\
\text { management }\end{array}$ \\
\hline $\begin{array}{l}\text { All } \\
\text { students }\end{array}$ & $2.50 \pm 0.29$ & $2.01 \pm 0.53$ & $2.61 \pm 0.48$ & $2.23 \pm 0.59$ & $3.05 \pm 0.44$ & $2.42 \pm 0.49$ & $2.69 \pm 0.44$ \\
\hline First year & $2.59 \pm 0.29^{c}$ & $2.02 \pm 0.48$ & $2.70 \pm 0.47$ & $2.31 \pm 0.56^{\mathrm{c}}$ & $3.16 \pm 0.39^{\mathrm{b}}$ & $2.59 \pm 0.41^{\mathrm{a}, \mathrm{b}}$ & $2.77 \pm 0.47^{\mathrm{c}}$ \\
\hline $\begin{array}{l}\text { Second } \\
\text { year }\end{array}$ & $2.49 \pm 0.29$ & $1.98 \pm 0.45$ & $2.56 \pm 0.45$ & $2.31 \pm 0.52^{\mathrm{d}}$ & $3.08 \pm 0.47$ & $2.35 \pm 0.53^{\mathrm{d}}$ & $2.66 \pm 0.41$ \\
\hline Third year & $2.47 \pm 0.28$ & $2.03 \pm 0.59$ & $2.59 \pm 0.46$ & $2.22 \pm 0.59$ & $2.96 \pm 0.40$ & $2.30 \pm 0.41^{\mathrm{e}}$ & $2.74 \pm 0.43$ \\
\hline $\begin{array}{c}\text { Fourth } \\
\text { year }\end{array}$ & $2.45 \pm 0.30$ & $2.00 \pm 0.60$ & $2.59 \pm 0.57$ & $2.08 \pm 0.70$ & $3.01 \pm 0.48$ & $2.43 \pm 0.60$ & $2.61 \pm 0.43$ \\
\hline$F$ value & 3.095 & 0.153 & 1.984 & 7.305 & 3.43 & 10.637 & 4.206 \\
\hline
\end{tabular}

The values are expressed as means $\pm \mathrm{SD}$, and one-way analysis of variance (ANOVA) and multiple comparison procedures using the Scheffe test were conducted

${ }^{\text {a }} P<0.05$ year 1 versus year 2

b $P<0.05$ year 1 versus year 3

c $P<0.01$ year 1 versus year 4

${ }^{\mathrm{d}} P<0.01$ year 2 versus year 4

e $P<0.01$ year 3 versus year 4

\section{BMI}

The mean BMI for the whole participant cohort was $20.9 \pm 2.3$, with the males having a mean score of $21.5 \pm$ 2.5 and the females having a mean score of $20.0 \pm 1.7$. Significant differences existed between the males and the females in BMI $(t=4.942 ; P<0.001)$. The BMI results for the participants revealed that $83.6 \%$ were in the normal range, $11.2 \%$ were underweight, and $5.2 \%$ were overweight. Focusing on the year, 82.4, 88.1, 80.6, and $85.4 \%$ had a normal BMI, $13.5,7.4,6.5$, and $6.0 \%$ were underweight, and $4.1,4.5,12.9$, and $8.6 \%$ were overweight, for first year students, second year students, third year students, and fourth year students, respectively. Of the female students, $80.2 \%$ had a normal BMI, $18.8 \%$ were underweight, and $1.0 \%$ were overweight. Comparatively, $85.6 \%$ of the male students had a normal BMI, $6.6 \%$ were underweight, and $7.8 \%$ were overweight. There was no significant correlation between the overall HPLP-II score and BMI by Pearson's correlation analysis.

\section{Living with family (yes/no)}

Table 3 reports the distribution of the HPLP-II scores and subscales according to whether or not students were living with family. There was no significant difference between the students living with family and those not living with family in the overall HPLP-II score. The percentage of students living with family was $56 \%(n=110)$ for males and $48 \%(n=57)$ for females, and students living with family had a nutrition score $(2.55 \pm 0.43, P<0.05)$ that was significantly higher than the score for those not living with family $(2.30 \pm 0.47)$.

In the items on the nutrition subscale, more students living with family than not $(23.3$ vs. $18.9 \%, P<0.01)$ reported that they "eat 3-5 servings of vegetables each day" and "eat only 2-3 servings from the meat, poultry, fish, dried beans, eggs, and nuts group each day" (35.2 vs. $23.8 \%, P<0.01)$. The students living with family had better nutrition habits; they were more likely to report "eat breakfast" (63.2 vs. $48.3 \%, P<0.01)$, "read labels to identity nutrition, fats, and sodium content in packaged food" (16.8 vs. 13.9\%, $P>0.05$ ), and "eat 2-3 servings of milk, yogurt or cheese each day" ( 8.0 vs. $5.6 \%, P>0.05$ ). No significant differences were established between students living with family and gender $\left(\chi^{2}=1.53, P>0.05\right)$, or between students living with family and year $\left(\chi^{2}=0.07, P>0.05\right)$ by $\chi^{2}$ tests.

\section{Income}

The income of participants was categorized into four ranges: (1) no income from a regular or part-time job $(n=$ $148,47.1 \%)$; (2) less than J¥500,000 ( $n=122,38.9 \%)$; (3) $J ¥ 500,000-1,000,000 \quad(n=38,12.1 \%)$; and (4) greater than $\mathrm{J} ¥ 1,000,000(n=6,2.0 \%)$. A significant correlation was shown between income and IR by the Pearson's correlation analyses.

\section{Multiple comparisons among groups}

Multiple regression analysis of the six demographic variables with the overall HPLP-II score and six health-promoting 
Table 3 Distribution of health-promoting lifestyle profile II (HPLP-II) scores according to family category and gender

\begin{tabular}{|c|c|c|c|c|c|c|c|}
\hline & Overall HPLP-II & $\begin{array}{l}\text { Health } \\
\text { responsibility }\end{array}$ & $\begin{array}{l}\text { Spiritual } \\
\text { growth }\end{array}$ & $\begin{array}{l}\text { Physical } \\
\text { activity }\end{array}$ & $\begin{array}{l}\text { Interpersonal } \\
\text { relations }\end{array}$ & Nutrition & $\begin{array}{l}\text { Stress } \\
\text { management }\end{array}$ \\
\hline \multicolumn{8}{|c|}{ Living with family } \\
\hline No & $2.50 \pm 0.30$ & $2.00 \pm 0.50$ & $2.58 \pm 0.47$ & $2.31 \pm 0.57$ & $3.11 \pm 0.41$ & $2.30 \pm 0.47$ & $2.70 \pm 0.49$ \\
\hline Yes & $2.51 \pm 0.28$ & $2.02 \pm 0.47$ & $2.65 \pm 0.46$ & $2.15 \pm 0.54$ & $3.00 \pm 0.42$ & $2.55 \pm 0.43^{*}$ & $2.69 \pm 0.41$ \\
\hline$t$ value & 0.737 & 0.472 & 0.519 & 0.461 & 1.268 & $2.332^{*}$ & 0.025 \\
\hline \multicolumn{8}{|l|}{ Gender } \\
\hline Male & $2.50 \pm 0.32$ & $1.94 \pm 0.52$ & $2.58 \pm 0.50$ & $2.44 \pm 0.55^{* * *}$ & $2.97 \pm 0.42$ & $2.34 \pm 0.49$ & $2.70 \pm 0.49$ \\
\hline Female & $2.51 \pm 0.25$ & $2.08 \pm 0.41 * *$ & $2.64 \pm 0.40$ & $2.00 \pm 0.50$ & $3.14 \pm 0.39 *$ & $2.52 \pm 0.38 * *$ & $2.69 \pm 0.39$ \\
\hline$t$ value & 0.789 & $2.757 * *$ & 0.628 & $5.276 * * *$ & $2.55^{*}$ & $2.872 * *$ & 1.101 \\
\hline
\end{tabular}

The values are expressed as means $\pm \mathrm{SD}$, and $t$-tests were conducted. $* P<0.05, * * P<0.01, * * * P<0.001$

Table 4 Independent baseline predictors of health-promoting lifestyle profile II (HPLP-II) and demographic data of participants

\begin{tabular}{|c|c|c|c|c|c|c|c|}
\hline Variable & $\begin{array}{l}\text { Overall } \\
\text { HPLP-beta }\end{array}$ & $\begin{array}{l}\text { Health } \\
\text { responsibility } \\
\text { beta }\end{array}$ & $\begin{array}{l}\text { Spiritual } \\
\text { growth } \\
\text { beta }\end{array}$ & $\begin{array}{l}\text { Physical } \\
\text { activity beta }\end{array}$ & $\begin{array}{l}\text { Interpersonal } \\
\text { relations beta }\end{array}$ & $\begin{array}{l}\text { Nutrition } \\
\text { beta }\end{array}$ & $\begin{array}{l}\text { Stress } \\
\text { management } \\
\text { beta }\end{array}$ \\
\hline Sex (male/female) & 0.036 & $0.174 * *$ & -0.028 & $-0.338 * * *$ & $0.158 * *$ & $0.132 * *$ & 0.084 \\
\hline Age (years) & 0.089 & $0.193 * *$ & 0.100 & 0.001 & -0.086 & 0.05 & 0.058 \\
\hline Living with family (yes/no) & 0.011 & 0.070 & 0.006 & -0.003 & $-0.130 *$ & 0.108 & -0.029 \\
\hline Income $(1-4)$ & 0.045 & -0.022 & 0.053 & 0.005 & $0.136^{*}$ & -0.005 & 0.012 \\
\hline Year (1-4) & $-0.235^{* *}$ & -0.076 & $-0.212 * *$ & -0.104 & -0.126 & $-0.276 * * *$ & -0.076 \\
\hline BMI & -0.007 & 0.006 & 0.029 & 0.015 & -0.084 & 0.015 & -0.021 \\
\hline$R^{2}$ & 0.044 & $0.061^{*}$ & 0.033 & $0.115^{* * *}$ & $0.090 * *$ & $0.109 * * *$ & 0.015 \\
\hline
\end{tabular}

$* P<0.05$, ** $P<0.01$, *** $P<0.001$; using multiple regression analysis

lifestyle subscales scores was performed to determine which independent variables were good predictors of a healthy lifestyle in the participants. With all six variables in the regression model, 4.4\% $(P>0.05), 6.1 \%(P<$ $0.05), 3.3 \%(P>0.05), 11.5 \%(P<0.001), 10.9 \%(P<$ $0.001), 9.0 \%(P<0.01)$, and $1.5 \%(P>0.05)$ of the variance in the participants' overall HPLP-II, HR, SG, PA, IR, N, and SM, respectively, were explained by the model (Table 4).

Several highly significant correlations were found for the independent variables, and a significant negative effect of year on the overall HPLP-II score was found. Significant effects for sex and age on HR; year on SG; sex on PA; sex, living with family, and income on IR; and sex and year on $\mathrm{N}$ were found. No significant effect of demographic variables on SM was found.

\section{Discussion}

This study focused on the year level of university students, while aiming to explore the various levels of the HPLP-II in Japanese university students with different demographic characteristics. Our data showed that during the first year of enrollment in a general university course, they tended to practice more health-promoting lifestyles when compared to students in other years. A significant negative correlation was found between HPLP-II and year, but no such correlation was found for age. This finding suggests that the students may have had self-care and knowledge about health-promoting lifestyles at university continually. In the first year of enrollment they continued health-promoting lifestyles such as participating in sports club activities and friendships that they had during high school. Few studies have reported on university students' HPLP-II and year according to the year in 4-year courses. Previous studies using the HPLP-II found a significant positive correlation between the HPLP-II and age in university students [1416]. In contrast, we found a significant negative correlation between the HPLP-II and year, and no correlation with age. The results for students in intermediate year levels were similar to findings reported by Al-Kandari et al. [14], who examined HPLP-II and demographic variables in nursing course students in two years of their course. Duffy et al. [17-20] and others [17-20] reported that demographic factors made a modest contribution to explaining healthpromoting lifestyles, and age and education were related to health-promoting lifestyles. 
In the present study, the university students' highest mean scores among the six health-promoting lifestyles were for IR and SM. The lowest scores were for HR and PA. Our data showed that interpersonal relationships and stress management were higher, but health responsibility and physical activities were lower than in other groups previously studied [21]. In Japan, physical education is not a compulsory course at some universities. In our university there has been no compulsory course in physical education for 10 years. However, most of the present study participants (more than 90\%) chose the physical education course in their first year. Thus, most of the students could have led a sedentary lifestyle during their second, third, and fourth years. It may be that physical inactivity is associated with poor physical activities, irregular eating habits, and insufficient nutrition, leading to underweight status. These findings suggest that continuing physical education at university may have a positive effect on health promotion and disease prevention.

Our results for the comparison between male and female students were similar to the results of previous studies [2224]. There were higher nutrition scores for students living with family than for those not living with family. The data suggest that students living with family have a better nutritional balance in their daily meals.

Our findings point to the need for more research into health promotion behaviors, study style, degree programs, social environment or activities, and recreational activities during students' university and daily lives. Future studies of other life stages, such as the populations of junior high school students, senior high school students, graduate students, young adults, and adults will be needed to clearly show how changing the life conditions or environment of university students influences their health-related behaviors.

Acknowledgments The authors would like to thank all students who participated in this study, and technical supporter Ms. Akiyo Kikuchi for data collection and clerical support.

\section{References}

1. US Department of Health and Human Services. Healthy People 2010. With understanding and improving health and objectives for improving health. 2nd ed. Washington, DC: US Government Printing Office; 2000.

2. Sakurai H. Healthy Japan 21. J Jpn Med Assoc. 2001;126: 1542-3.

3. American College Health Association. Healthy campus 2010: making it happen. Baltimore, MD: American College Health Association; 2002.

4. Perston DB, Green GW, Irwin PA. An assessment of college health nursing practice: a wellness perspective. J Commun Health Nurs. 1990;7:97-104.
5. World Health Organization. Coming of age: from facts to action for adolescent sexual and reproductive health. Geneva: WHO; 1977.

6. Fujii T, Ohsawa I, Nozawa A, Mori K, Kagaya M, Kajioka T, et al. The association of physical activity level characteristics and other lifestyle with obesity in Nagoya University alumni, Japan. Scand J Med Sci Sports. 1998;8:57-62.

7. Teiji N. The integration of school nutrition program into health promotion and prevention of lifestyle-related diseases in Japan. Asia Pac J Clin Nutr. 2008;17(S1):349-51.

8. The American College Health Association. American College Health Association National College Health Assessment (ACHANCHA) Spring 2005 Reference Group Data Report. J Am Coll Health. 2006;55:5-16.

9. Hawks SR, Madanat HN, Merrill RM, Goudy MB, Mitagawa T. A cross-cultural analysis of 'motivation for eating' as a potential factor in the emergence of global obesity: Japan and the United States. Health Promot Int. 2003;18:153-61.

10. Werch (Chad) CE, Bian H, Moore MJ, Ames S, DiClemente CC, Weiler RM. Brief multiple behavior interventions in a college student health care clinic. J Adolesc Health. 2007;41:577-85.

11. World Health Organization. Obesity: preventing and managing the global epidemic report of a WHO consultation on Obesity. Geneva: WHO; 1997.

12. Walker SN, Sechrist KR, Pender NJ. The health promoting lifestyle profile: development and psychometric charactristics. Nurse Res. 1978;36:76-81.

13. Wei CN, Yonemitsu H, Harada K, Miyakita T, Omori S, Miyabayashi $\mathrm{T}$, et al. A Japanese language version of the health-promoting lifestyle profile. Jan J Hyg. 2000;54:597-606.

14. Al-Kandari F, Vidal VL, Thomas D. Health-promoting lifestyle and body mass index among college of nursing students in Kuwait: a correlational study. Nurs Health Sci. 2008;10:43-50.

15. AI-Kandari YY. Prevalence of obesity in Kuwait, its relation to sociocultural variables. Obes Rev. 2006;7:147-54.

16. Wai-Hing $\mathrm{CH}$. The health-promoting lifestyles of undergraduate nurses in Hong Kong. J Prof Nurs. 2002;18:101-11.

17. Duffy ME, Rossow R, Maricela H. Correlates of health-promoting activities in employed Mexican American women. Nurs Res. 1996;45:18-24.

18. Brown JS, McCreedy M. The hale elderly: health behavior and its correlates. Res Nurs Health. 1986;9:317-29.

19. Prochaska TR, Leventhal EA, Leventhal H, Keller ML. Health practices and illness cognition in young, middle age and elderly adults. J Gerontol. 1985;40:569-78.

20. Walker SN, Volken K, Sechrist KR, Pender NJ. Health-promoting lifestyles of older adults: comparisons with young and middle-aged adults, correlates and patterns. Adv Nurs Sci. 1988;11: 76-90.

21. Larouche R. Determinants of college students' health-promoting lifestyles. Clin Excell Nurse Pract. 1998;2:35-44.

22. Lee RL, Loke AJ. Health-promoting behaviors and psychosocial well-being of university students in Hong Kong. Public Health Nurs. 2005;22:209-20.

23. Jadack RA, Hyde JS, Keller ML. Gender and knowledge about HIV, risky sexual behavior, and safer sex practices. Res Nurs Health. 1995;18:313-24.

24. Oleckno WA, Blacconiere MJ. Wellness of college students and differences by gender, race and grade. Coll Stud J. 1990;24: $421-9$. 